\title{
Pendidikan Kesehatan Terintegrasi di Desa Anggadita Kabupaten Karawang
}

\author{
Hidayati $^{1 *}$, Lelly Qadariah ${ }^{1}$, Arovah Widiani $^{2}$ \\ ${ }^{1}$ Universitas Muhammadiyah Prof. Dr. Hamka., Jl. Tanah Merdeka, Pasar Rebo Jakarta Timur, Jl. J1. KH. \\ ${ }^{2}$ Universitas Muhammadiyah Jakarta, Jl. Limau II/1 Kebayoran Baru Jakarta Selatan, Ahmad Dahlan, \\ Ciputat, Cireundeu, Ciputat Timur \\ *Email: hidayati@uhamka.ac.id
}

\begin{abstract}
Abstrak
Ketersediaan alam dengan adanya sungai Citarum yang membentang diwilayah Desa Anggadita memberikan keuntungan dan permasalahan tersendiri bagi masyarakatnya. Pemanfaatan Sungai Citarum seharusnya diiringi dengan kesadaran masyarakat akan kebersihan lingkungan yang merupakan bagian dari perilaku hidup bersih dan sehat (PHBS), perbedaan karakteristik masyarakat yang ada di Desa Anggadita menyebabkan disparitas dalam masalah kesehatan, PHBS belum tercermin dari pembiasaan masyarakat sehari-hari dan belum adanya pendidikan kesehatan bagi masyarakat di Desa Anggadita. Pendidikan kesehatan terintegrasi yang dimaksudkan adalah perpaduan metode pendidikan kesehatan dalam pelaksanaanya seperti ceramah, pelatihan, demonstrasi dan pemeriksaan kesehatan serta meleburkan lapisan sosial masyarakat yang terdiri dari kelompok umur yang berbeda dengan metode dan teknik yang berbeda pula. Kelompok umur dewasa dan lansia metode pendidikan kesehatan yang dilakukan dengan pemberian KIE pencegahan penyakit hipertensi dan diabetes dan serta pemeriksaan tekanan darah dan pemeriksaan gula darah sewaktu, sedangkan untuk kelompok usia sekolah (Sekolah Dasar) dilakukan pelatihan kader kesehatan melalui pelatihan dokter cilik. Pendidikan kesehatan memberikan dorongan peningkatan kesadaran, membangkitkan kepedulian, merangsang tindakan untuk keterlibatan masyarakat dan komitmen untuk reformasi sosial yang penting untuk sukses dan mewujudkan PHBS sesuai dengan hasil yang dicapai pada kegiatan ini yaitu tumbuhnya kesadaran pada kelompok dewasa dan lansia untuk menjaga kesehatan melalui pemeriksaan kesehatan dan terjadinya peningkatan pengetahuan mengenai PHBS Sekolah pada kelompok usia sekolah melalui pelatihan dokter cilik.
\end{abstract}

Kata kunci: Pendidikan Kesehatan, KIE, PHBS, Hypertensi, Diabetes

\begin{abstract}
The availability of nature with the existence of the Citarum River which stretches in the village area of Anggadita provides its own advantages and problems for the community. Utilization of the Citarum River should be accompanied by public awareness of environmental hygiene which is part of clean and healthy lifestyle (PHBS), differences in the characteristics of the people in Anggadita Village cause disparities in health problems, PHBS has not been reflected in daily habituation and absence health education for the people in Anggadita Village. Integrated health education is intended to be a combination of health education methods in its implementation such as lectures, training, demonstrations and health checks as well as fusing social layers of society consisting of different age groups with different methods and techniques. The age group of adults and the elderly method of health education carried out by giving communication information and education on prevention of hypertension and diabetes and as well as blood pressure checks and blood sugar checks while, while for school age groups (Elementary School) health cadre training was conducted through the training of young doctors. Health education provides an impetus to increase awareness, raise awareness, stimulate actions for public involvement and commitment to social reform that are important for success and realize PHBS in accordance with the results achieved in this activity, namely growing awareness in adult and elderly groups to maintain health through health checks and there is an increase in knowledge about PHBS schools in school age groups through the training of child doctors.
\end{abstract}

Keywords: Health Education, Information Communication and Education on Prevention, Hypertension, Diabetes. 
Format Sitasi: Hidayati, H., Lelly, Q. \& Widiani, A. (2019). Pendidikan Kesehatan Terintegrasi di Desa Anggadita Kabupaten Karawang. Jurnal Solma, 08(1), 80-89. Doi: http://dx.doi.org/10.29405/solma.v8i1.2825

Diterima: 23 Desember 2018 | Revisi: 14 Maret 2019 | Dipublikasikan: 30 April 2019.

\section{PENDAHULUAN}

Kesehatan merupakan salah satu hak asasi yang fundamental bagi setiap penduduk. Selain sebagai hak asasi, kesehatan juga merupakan investasi. Mengingat hal tersebut, hendaknya kesehatan dapat dijadikan sebagai tanggung jawab bersama yang perlu diperjuangkan oleh berbagai pihak bukan hanya jajaran kesehatan semata (Kementerian Kesehatan RI, 2009). Salah satu bentuk ikhtiar untuk mewujudkannya adalah melalui pendidikan kesehatan.

Pendidikan kesehatan adalah upaya untuk mempengaruhi orang lain, baik individu, kelompok, atau masyarakat, agar melaksanakan perilaku hidup sehat. Sedangkan secara operasional, pendidikan kesehatan merupakan suatu kegiatan untuk memberikan dan atau meningkatkan pengetahuan, sikap, dan praktek masyarakat dalam memelihara dan meningkatkan kesehatan mereka sendiri. Proses belajar dalam pendidikan kesehatan merupakan proses terjadinya perubahan kemampuan pada subjek belajar dengan keluaran yang diharapkan adalah kemampuan sebagai hasil perubahan perilaku dari sasaran didik Peningkatan pegetahuan yang terjadi setelah diberikan pendidikan kesehatan merupakan salah satu aspek kemampuan yang dicapai oleh sasaran didik sebagai akibat adanya proses belajar (Notoadmojo, 2010).

Kurangnya pengetahuan mengenai informasi-informasi kesehatan dapat menimbulkan ketidaktahuan masyarakat untuk mengidentifikasi masalah-masalah kesehatan seperti penyakit degeneratif yang terus meningkat kejadiannya seperti hipertensi dan diabetes.

Data dari World Health Organization (WHO) dan the International Society of Hypertension (ISH), saat ini terdapat 600 juta penderita hipertensi di seluruh dunia, dan 3 juta diantaranya meninggal setiap tahunnya, dari 10 penderita tersebut tidak mendapatkan pengobatan secara adekuat (Mardhiah, Abdullah, Masyarakat, K., Muhammadiah, \& Aceh, 2013). Berbagai penelitian epidemiologi menunjukkan adanya kecenderungan peningkatan angka insidens dan prevalensi Dibetes Melitus (DM) tipe-2 di berbagai penjuru dunia. WHO memprediksi adanya peningkatan jumlah penyandang diabetes yang cukup besar 
untuk tahun-tahun mendatang. Untuk Indonesia, WHO memprediksi kenaikan jumlah pasien dari 8.4 juta pada tahun 2000 menjadi sekitar 21,3 juta pada tahun 2030 (Windasari, Wibowo, \& Afandi, 2014).

Penanggulangan hipertensi dan DM ini penting dilakukan khususnya dalam usahausaha pencegahan yang dapat dilakukan melalui pendidikan kesehatan. Mengingat bahwa DM dan Hipertensi akan memberikan dampak terhadap kualitas sumber daya manusia dan peningkatan biaya kesehatan yang cukup besar. Melalui pendidikan kesehatan yang terencana, individu dan masyarakat akan lebih patuh dalam penatalakasanaan pencegahan maupun perawatan penyakit hipertensi dan diabetes. Pendidikan kesehatan adalah salah satu cara untuk meningkatkan kepatuhan (Delamater \& M, 2006)

Tujuan dari pengabdian masyarakat ini adalah merubah perilaku masyarakat untuk hidup sehat dengan target terjadinya kesadaran dan meningkatnya pengetahuan kesehatan masyarakat untuk berperilaku hidup bersih dan sehat.

\section{MASALAH}

Desa Anggadita Kabupaten Karawang merupakan suatu wilayah pedesaan yang dilalui sungai Citarum. Desa Anggadita terdiri atas beberapa dusun yang masing-masing dusun terdiri atas RW dan RT. Penduduk desa tersebut merupakan masyarakat terdegradasi dari masyarakat yang agraris menjadi masyarakat industri dimana sebagian penduduk di wilayahnya (Dusun Sukajaya) masih bekerja di bidang agraris (bertani dan berternak) sebagian lainnya menjadi buruh di pabrik sekitar wilayah tersebut (Dusun Sukamulya).

Perbedaan Karakteristik tersebut memberikan perbedaan pada perilaku kesehatan masyarakat sekitarnya. Masyarakat Dusun Sukamulya cenderung memiliki tingkat pendidikan yang lebih tinggi dari masyarakat Dusun Sukajaya, dan memiliki kebiasaankebiasaan kurang aktifitas fisik, stres karena pekerjaan, dan mengkonsumsi makanan instan. Selain itu juga Desa Sukamulya memiliki potensi kader kesehatan yang tersebar di sekolah-sekolah dasar (SD) dengan adanya usaha kesehatan sekolah yang sudah berjalan namun kurang tersentuh pembekalan pengetahuan mengenai perilaku hidup bersih dan sehat itu sendiri.

Perilaku kurang aktifitas fisik dan mengkonsumsi makanan instan yang cenderung kandungan gizinya lebih banyak mengandung garam yang memicu kejadian hpertensi, selain menambah berat badan yang bisa memicu penyakit degeneratif lainnya seperti diabetes.

\section{METODE PELAKSANAAN}

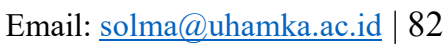


Teknik pengumpulan data untuk kegiatan ini dilakukan dengan wawancara dan observasi. Wawancara dilakukan dengan stake holder kesehatan dalam hal ini koordinator Promkes Puskesmas Anggadita dan pejabat pemerintah Desa Anggadita yang diwakili Sekertaris Desa dan Kepala Dusun Sukamulya. Observasi dilakukan melalui pengamatan kegiatan sehari-hari masyarakat Desa Anggadita bersama tim dalam pengamatan satu hari pada tanggal 11 Oktober 2018. Gambaran kegiatannya dapat dilihat pada tabel .1.

Tabel 1. Kegiatan Pengabdian Masyarakat Pendidikan Kesehatan Terintegrasi Di Desa Anggadita Kabupaten Karawang

\begin{tabular}{|c|c|c|c|c|c|}
\hline $\begin{array}{c}\text { Waktu } \\
\text { Pelaksan } \\
\text { aan }\end{array}$ & $\begin{array}{l}\text { Lokasi } \\
\text { Kegiatan }\end{array}$ & Nama Kegiatan & $\begin{array}{c}\text { Lamanya } \\
\text { Pelaksanaan }\end{array}$ & Bentuk Kegiatan & Pelaksana \\
\hline $\begin{array}{l}11 \\
\text { Oktober } \\
2018\end{array}$ & $\begin{array}{l}\text { Desa } \\
\text { Anggadita } \\
\text { Kabupaten } \\
\text { Karawang } \\
\text { Jawa Barat }\end{array}$ & $\begin{array}{l}\text { Kunjungan TIM } \\
\text { KKN Citarum } \\
\text { Harum Sektor } 18 \\
\text { UHAMKA }\end{array}$ & 1 (satu) hari & $\begin{array}{lr}\text { Wawancara pihak } \\
\text { terkait } \\
\text { (pemerintahan dan } \\
\text { stake holder } \\
\text { kesehatan) dan } \\
\text { Observasi wilayah } \\
\text { dan masyarakat } \\
\text { Desa Anggadita }\end{array}$ & $\begin{array}{c}\text { Seluruh Tim } \\
\text { (Tim Kesling, } \\
\text { PAUD \& Pos } \\
\text { Kesehatan) }\end{array}$ \\
\hline $\begin{array}{l}12-13 \\
\text { Oktober } \\
2018\end{array}$ & $\begin{array}{l}\text { UHAMKA } \\
\text { Jl. Raya } \\
\text { Pasar Rebo, } \\
\text { Jak-Tim }\end{array}$ & $\begin{array}{l}\text { Perencanaan } \\
\text { Kegiatan }\end{array}$ & 2 (dua) hari & $\begin{array}{l}\text { Rapat dan } \\
\text { penyusunan } \\
\text { proposal kegiatan }\end{array}$ & $\begin{array}{l}\text { Tim Pos } \\
\text { Kesehatan }\end{array}$ \\
\hline $\begin{array}{l}15 \quad-31 \\
\text { Oktober } \\
2018\end{array}$ & $\begin{array}{l}\text { Desa } \\
\text { Angadita \& } \\
\text { UHAMKA }\end{array}$ & $\begin{array}{l}\text { Mengurus Izin } \\
\text { Kegiatan }\end{array}$ & $\begin{array}{l}16 \text { (enam } \\
\text { belas) hari }\end{array}$ & \begin{tabular}{lr}
\multicolumn{2}{c}{ Pembuatan surat izin } \\
dan & Koordinasi \\
dengan & pihak-pihak \\
terkait &
\end{tabular} & $\begin{array}{l}\text { Tim Pos } \\
\text { Kesehatan }\end{array}$ \\
\hline $\begin{array}{l}5-9 \\
\text { November } \\
2018\end{array}$ & $\begin{array}{l}\text { UHAMKA } \\
\text { Jl. Limau } \\
\text { II/1 Jakarta } \\
\text { Selatan }\end{array}$ & $\begin{array}{l}\text { Persiapan } \\
\text { Kegiatan }\end{array}$ & 5 (lima) hari & $\begin{array}{l}\text { Pembelian alat, } \\
\text { pembuatan spanduk, } \\
\text { pembuatan media, } \\
\text { dan persiapan } \\
\text { lainnya }\end{array}$ & $\begin{array}{l}\text { Tim Pos } \\
\text { Kesehatan }\end{array}$ \\
\hline $\begin{array}{l}10 \\
\text { November } \\
2018\end{array}$ & $\begin{array}{l}\text { Balai Desa } \\
\text { Anggadita }\end{array}$ & $\begin{array}{l}\text { Pelaksanaan } \\
\text { Kegiatan }\end{array}$ & $\begin{array}{c}\text { 1/2 (setengah) } \\
\text { hari }\end{array}$ & $\begin{array}{l}\text { Pemeriksaan } \\
\text { Tekanan Darah Dan } \\
\text { Pemeriksaan gula } \\
\begin{array}{l}\text { Darah } \\
\text { diikuti } 50 \text { Sewaktu } \\
\text { peserta }\end{array}\end{array}$ & $\begin{array}{l}\text { Tim Pos } \\
\text { Kesehatan }\end{array}$ \\
\hline & $\begin{array}{l}\text { Balai Desa } \\
\text { Anggadita }\end{array}$ & $\begin{array}{l}\text { Pelaksanaan } \\
\text { Kegiatan }\end{array}$ & $1 / 2$ hari & $\begin{array}{l}\text { Pemberian KIE } \\
\text { mengenai Penyakit } \\
\text { Diabetes diikuti } 30 \\
\text { orang peserta }\end{array}$ & $\begin{array}{l}\text { Tim Pos } \\
\text { Kesehatan }\end{array}$ \\
\hline
\end{tabular}




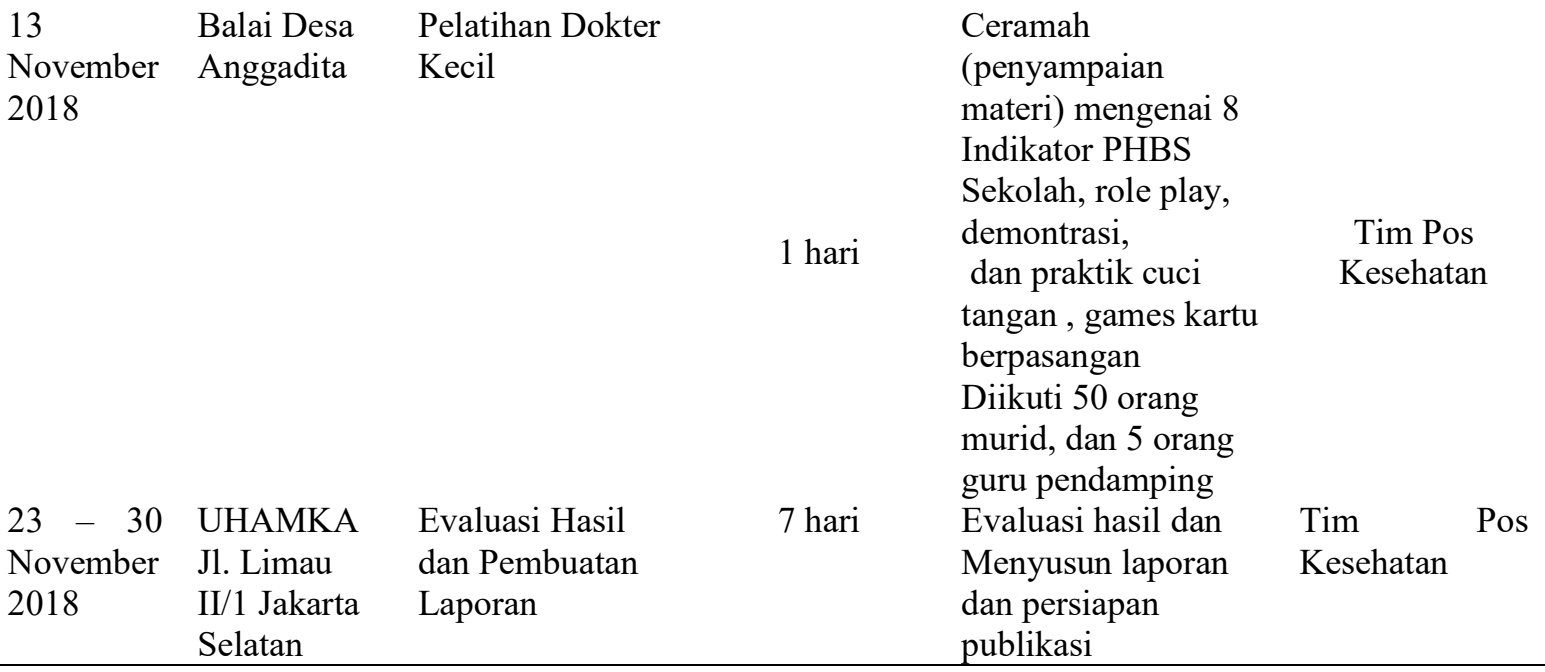

Teknik analisa data yang dilakukan pada pendidikan kesehatan di kelompok umur dewasa dan lansia melalui pemeriksaan kesehatan dilakukan pencatatan hasil sesuai pengukuran, dan dianalisa berdasarkan univariat (distribusi dan frekuensi) sedangkan metode pelatihan dokter cilik dilakukan pretest dan posttest.

\section{HASIL DAN PEMBAHASAN}

Hasil pemeriksaan kesehatan yang dilakukan berdasarkan jenis kelamin jumlah perempuan lebih banyak dari laki-laki baik pada pemeriksaan tekanan darah maupun pengukuran gula darah sewaktu. Distribusi peserta pemeriksanaan kesehatan berdasarkan jenis kelamin dapat dilihat pada tabel 2. dan tabel 3.

Tabel 2. Distribusi Peserta Pemeriksaan Kesehatan (Tekanan Darah) Berdasarkan Jenis Kelamin

\begin{tabular}{lcc}
\hline \multicolumn{1}{c}{ Jenis Kelamin } & Jumlah & \% \\
\hline Laki-laki & 13 & $26 \%$ \\
Perempuan & 37 & $74 \%$ \\
Jumlah & $\mathbf{5 0}$ & $\mathbf{1 0 0} \%$ \\
\hline
\end{tabular}

Sumber: Data Primer, 2018

Tabel 3. Distribusi Peserta Pemeriksaan Kesehatan (Gula Darah) Berdasarkan Jenis Kelamin

\begin{tabular}{lcc}
\multicolumn{1}{c}{ Jenis Kelamin } & Jumlah & $\%$ \\
\hline Laki-laki & 13 & $27 \%$ \\
Perempuan & 35 & $73 \%$ \\
\hline
\end{tabular}




$\begin{array}{lll}\text { Jumlah } & 48 & 100 \%\end{array}$

Sumber: Data Primer, 2018

Berdasarkan tabel 2. dan tabel 3. dapat terlihat bahwa perempuan lebih banyak melakukan pemeriksaan kesehatan, $74 \%$ pada pemeriksaan tekanan darah dan $73 \%$ pada pemeriksaan gula darah sewaktu. Hal ini tidak sejalan dengan profile kesehatan Indonesia tahun 2015 yang menyatakan jumlah penduduk Indonesia dari jenis kelamin laki-laki lebih banyak (128. 366.718) dari jenis kelamin perempuan (127.094.968) (Ministry of Health Republic of Indonesia, 2016), demikian juga pada tahun 2016 rasio penduduk laki-laki lebih tinggi dibandingkan penduduk perempuan (terdapat 101 laki-laki diantara 100 perempuan (Kementrian Kesehatan Republik Indonesia, 2017). Hasil tersebut juga sesuai dengan penelitian (R.S \& Wardani, 2013) yang menyebutkan secara statitstik tidak ada hubungan antara jenis kelamin dengan perilaku pencarian pengobatan (R.S \& Wardani, 2013)

Namun berbeda dengan penelitian Syaikh, dkk (2007) secara alamiah laki-laki lebih malas untuk mencari pengobatan atau perhatian pada kondisi kesehatannya dikarenakan sifatnya yang maskulin, merasa kuat dan adanya kecenderungansistem layanan kesehatan yang lebih berpihak pada kelompok rentan seperti perempuan (Shaikh, Haran, Hatcher, \& Iqbal Azam, 2008).

Temuan lain dari kegiatan pemeriksaan kesehatan didapatkan adanya kecenderungan tekanan darah yang lebih tinggi pada laki-laki (rata-rata hasil pengukuran tekanan darah 130/90 -140/110 dari usia 27-35 tahun) sementara dari jenis kelamin perempuan lebih bersiko terhadap kejadian diabetes. Hal ini dibuktikan dengan hasil pengukuran gula darah sewaktu yang bersiko/tinggi (hasil $152 \mathrm{mg} / \mathrm{dl}$ dan $153 \mathrm{mg} / \mathrm{dl}$ ) didapatkan pada jenis kelamin perempuan dengan usia 17 dan 18 tahun.

Berdasarkan epidemiologi jenis kelamin juga merupakan variabel orang yang dapat mempengaruhi kejadian penyakit atau menjadi faktor risiko dari penyakit tertentu. Berdasarkan gender (jenis kelamin) kejadian hipertensi lebih banyak ditemui pada laki-laki dibandingan perempuan, namun akan meningkat kejadiannya pada perempuan dengan bertambahnya usia pada fase awal menoupause. Sedangkan untuk diabetes lebih berisiko dari jenis kelamin perempuan (Short, Yang, \& Jenkins, 2013).

Pemberian informasi kesehatan untuk pencegahan hipertensi dan diabetes dilakukan dengan metode ceramah dan pemberian media cetak berupa leaflet. Pemberian leaflet ini 
diharapkan dapat memperkuat ingatan masyarakat setelah penyuluhan melalui ceramah menjadi ingatan yang disimpan dalam jangka waktu lama (longlasting).

Keuntungan leaflet adalah dapat disimpan lama dan dapat dibaca berkali-kali. Kemudian informasi yang diberikan tidak bertele-tele langsung pada poin intinya saja. Memudahkan pembaca mengingat informasi yang diberikan dengan memberikan informasi yang utama dan langsung pada titik pusat pembahasan.

Berdasarkan ruang lingkup pendidikan kesehatan dapat dilakukan di institusi pendidikan. Pendidikan kesehatan di institusi pendidikan yang dilakukan adalah dengan kegiatan Pelatihan dokter kecil. Pelatihan ini melibatkan 5 sekolah dasar negeri yang ada di Desa Anggadita dengan jumlah siswa yang dilatih sebanyak 50 orang. "Dokter Kecil" adalah peserta didik yang memenuhi kriteria dan telah dilantik untuk ikut melaksanakan sebagian usaha pemeliharaan dan peningkatan kesehatan terhadap diri sendiri, teman, keluarga dan lingkungannya. Dokter kecil merupakan bagian dari program Usaha Kesehatan Sekolah (UKS) (Ayub, 2017)

Pelatihan dokter kecil ini diharapkan mampu membentuk kader kesehatan yang akan menjadi agent of change bagi kesehatan, khususnya masyarakat di Desa Anggadita. Pelatihan dilakukan dengan penyampaian materi oleh narasumber mengenai delapan indikator perilaku hidup bersih dan sehat di sekolah (PHBS). Penyampaian materi dilakukan dengan metode yang bermacam diantaranya ceramah, demonstrasi dan dalam bentuk permainan dengan melibatkan partisipasi aktif dari para peserta.

Pengukuran pengetahuan pada pelatihan dokter cilik ini dilakukan melalui pretest dan posttest mengenai 8 indikator PHBS Sekolah, yaitu: (1).Mencuci tangan dengan air bersih yang mengalir dan sabun, (2) Jajan di kantin sekolah yang sehat, (3) Membuang sampah pada tempatnya, (4) Mengikuti kegiatan olahraga di sekolah, (5) Menimbang berat badan dan mengukur tinggi badan setiap bulan, (6) Tidak merokok di sekolah, (7) Memberantas jentik nyamuk di sekolah secara rutin, (8) Buang air besar dan air kecil dijamban sekolah.

Hasil nilai terendah pada pretest adalah nilai1,3 dan yang tertinggi adalah nilai 6 , sedangkan pada postest nilai terendah yang didapatkan adalah 2,7 dan tertinggi adalah nilai 7,3. Skor/nilai pretest dan posttest ini dapat dilihat pada gambar 1 


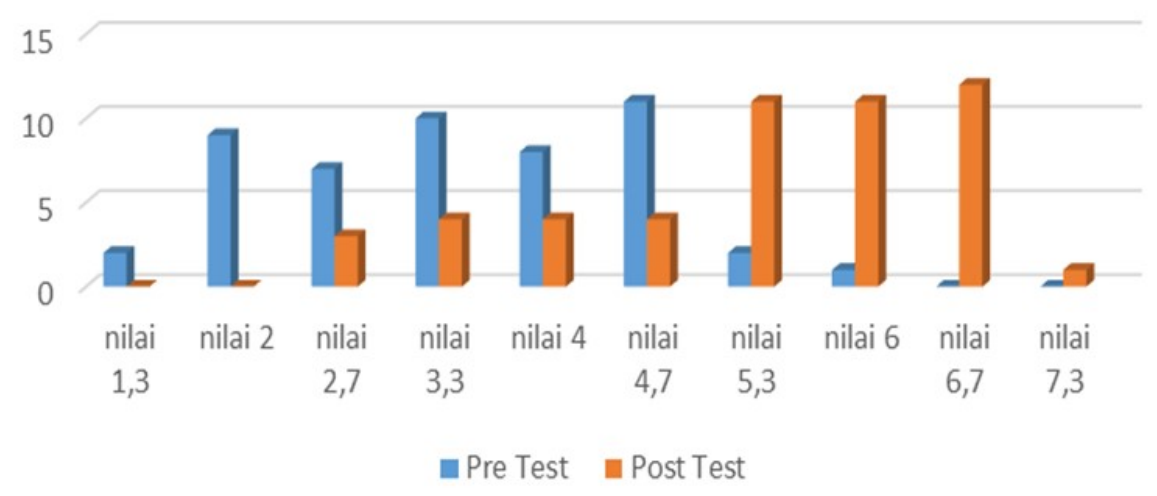

Gambar.1. Skor/Nilai Pretest dan Postest Pelatihan Dokter Kecil

Sumber: Data Primer, 2018

Berdasarkan gambar.1. pengukuran pengetahuan pada peserta pelatihan dokter kecil terjadi perubahan pengetahuan peserta pelatihan pada $92 \%$ peserta (46 orang) dan yang tidak mengalami perubahan pengetahuan sebanyak 4\% (2 orang) serta penurunan pengetahuan sebanyak 4\% juga ( 2 orang) dapat dilihat pada tabel 4.

Tabel 4. Perubahan .Pengetahuan Pengukuran Nilai Pengetahuan Pelatihan Dokter Cilik di Desa

\begin{tabular}{lcc}
$\begin{array}{c}\text { Perubahan } \\
\text { Pengetahuan }\end{array}$ & $\begin{array}{c}\text { Anggadita } \\
\text { Jumlah } \\
\text { ( orang) }\end{array}$ & \% \\
Nilai yang naik & 46 & 92 \\
Nilai yang Turun & 2 & 4 \\
Nilai Tetap & 2 & 4 \\
Jumlah & $\mathbf{5 0}$ & $\mathbf{1 0 0} \%$ \\
\hline
\end{tabular}

Sumber: Data Primer, 2018

Berdasarkan table 4. adanya peserta yang tidak mengalami perubahan pengetahuan dan bahkan penurunan pengetahuan ini bisa disebabkan oleh faktor yang mempengaruhipelatihan seperti gaya belajar dan waktu terbaik pelatihan. Riset menunjukkan bahwa tanpa relevansi, makna, dan emosi yang melekat pada materi yang diajarkan, para pembelajar tidak akan belajar. Adanya waktu terbaik untuk belajar yaitu ketika pembelajaran ada gunanya. Just-in-time training adalah pelatihan yang diberikan kapanpun dan di manapun pelatihan tersebut dibutuhkan (Mondy, 2009). 
Pendidikan kesehatan terintegrasi yang dilakukan melalui pemeriksaan kesehatan, pemberian informasi kesehatan maupun pelatihan merupakan kombinasi yang tepat dengan penggunaan waktu yang relatif singkat. Kirkpatrick and Kirkpatrick (2010) mengemukakan bahwa empat level evaluasi ini mewakili rangkaian pendidikan kesehatan. Masing-masing level bersifat penting dan memiliki dampak terhadap level berikutnya. Empat level evaluasi dalam model evaluasi Kirkpatrick meliputi level 1: reaction (evaluasi reaksi), level 2: learning (evaluasi pembelajaran), level 3: behavior (evaluasi perilaku) dan level 4: result (evaluasi hasil) (Kirkpatrick \& Kirkpatrick, 2007).

Kendala dalam melakukan pengabdian masyarakat ini pada setiap kegiatan berbedabeda macamnya. Jika pada pemeriksaan kesehatan dan pemberian informasi, peserta merasa terburu-buru karena kegiatan dilakukan pada hari libur yang seharusnya waktu tersebut digunakan untuk berkumpul dengan keluarga. Sedangkan pada pelatihan dokter cilik evaluasi yang dilakukan hanya evaluasi level pertama, yaitu reaksi peserta terhadap kegiatan yang berlangsung. Peserta yang hadir menunjukkan reaksi senang dengan adanya pendidikan kesehatan ini dengan menunjukkan gestur tubuh dengan adanya senyuman maupun kalimat verbal dengan mengatakan senang. Pada kegiatan pelatihan dokter cilik dilakukan evaluasi level-2 yaitu evaluasi pembelajaran dari hasil pretest dan posttest. Evaluasi level berikutnya tidak dilakukan mengingat keterbatasan waktu yang ada. Kegiatan untuk mengevaluasi hingga level 4 ini diperlukan waktu lama, dan sulit dilakukan dalam skema pengabdian saat ini.

Pendidikan kesehatan di Desa Anggadita juga mengajarkan penggunaan alat kesehatan. Dalam kegaitan pemeriksaan kesehatan melalui pengukuran tekanan darah dan pemeriksaan gula darah sewaktu menjadi proses pembelajaran penggunaan alat spyngomanometer untuk mengukur tekanan darah dan accucheck untuk mengukur darah gula sewaktu yang sudah ada (dimiliki) masyarakt (tim posyandu) untuk digunakan dalam posbindu yang akan dibentuk.Sedangkan pada pelatihan dokter cilik dilakukanpembelajaran mengukur tinggi badan menggunakan microtoise dan mengukur berat badan dengan timbangan badan. Penyebaran luasan informasi pencegahan hipertensi dan diabetes melalui leaflet serta tersedianya modul pelatihan dokter kecil bukan saja menciptakan proses belajar bagi masyarakat tetapi juga stakeholder kesehatan dalam pengadaan media yang diperlukan dalam pendidikan kesehatan. 


\section{Dokumentasi Kegiatan}

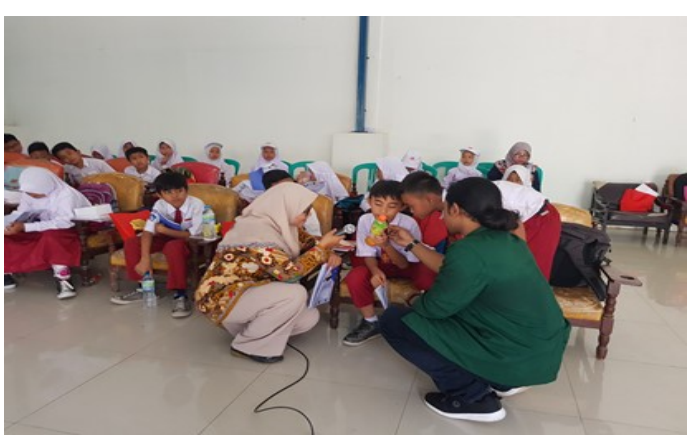

Gambar 2. Peserta pelatihan Dokter Cilik menyebutkan kandungan gizi dalam minuman (jajanan)

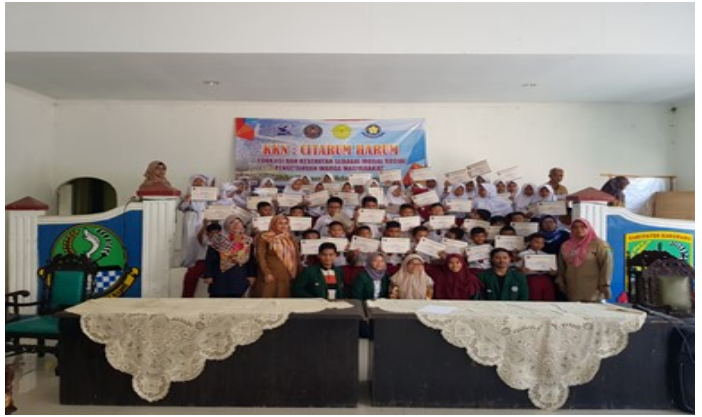

Gambar 3. Peserta Pelatihan Dokter Cilik Berfoto bersama dengan Tim Pengmas dan guru pendamping

\section{KESIMPULAN.}

Pendidikan kesehatan terintegrasi di Desa Anggadita Karawang merupakan proses belajar masyarakat melalui pemeriksaan kesehatan, penyebarluasan informasi kesehatan dan pelatihan yang menjadi bagian dari proses pendidikan kesehatan terencana. Dalam kegiatan nya diperlukan media yang tepat sebagai bagian proses pembelajarannya.

\section{UCAPAN TERIMAKASIH}

1. LPPM UHAMKA dan LPPM UMJ beserta jajarannya,

2. Kepala Desa Anggadita Bapak. H. Agustia Mulyana, Bapak Odi Kepala Dusun Sukamulya beserta jajaran pemerintahan Desa Anggadita

3. Kepala Puskesmas Anggadita: Bapak Memet Komarudin, SKM., MM.Kes

4. Koordinator Promkes Puskesmas Anggadita: Ibu Sulastri, SKM

5. Petugas UKS Puskesmas Anggadita: drg. Nunik Rafianti

6. Siswa-siswi SDN 1,2,3,4,5 Anggadita beserta Guru Pembina UKS

7. Masyarakat Desa Anggadita dan seluruh pihak yang telah berperan dalam pelaksanaan kegiatan pengabdian masyarakat ini yang tak dapat disebutkan satu persatu namanya

\section{DAFTAR PUSTAKA}

Ayub, M. (2017). Pelatihan, Modul dan Materi "Dokter Cilik."

Delamater, D., \& M, A. (2006). Improving Patient Adherence. Clinical Diabetes. Clinical Diabetes, 24(2). https://doi.org/https://doi.org/10.2337/diaclin.24.2.71

Kementerian Kesehatan RI, K. K. R. Undang-Undang Republik Indonesia No.36 Tahun 2009 Tentang Kesehatan. , (2009). 
Kementrian Kesehatan Republik Indonesia, K. K. R. I. (2017). Profil Kesehatan Indonesia Tahun 2016. https://doi.org/. https://doi.org/10.1111/evo.12990

Kirkpatrick, D. L., \& Kirkpatrick, J. D. (2007). Implementing the Four Levels: A Practical Guide for Effective Evaluation of Training Programs. Berrett-Koehler Publishers.

Mardhiah, A., Abdullah, A., Masyarakat, K., Muhammadiah, U., \& Aceh, B. (2013). Pendidikan Kesehatan Dalam Peningkatan Pengetahuan, Sikap Dan Keterampilan Keluarga Dengan Hipertensi - Pilot Study. Jurnal Ilmu Keperawatan.

Ministry of Health Republic of Indonesia, M. of H. R. of I. (2016). Indonesia Health Profile 2015.

Notoadmojo, S. (2010). Ilmu perilaku kesehatan. Jakarta: Rineka Cipta.

R.S, K., \& Wardani, Y. (2013). Faktor-Faktor Yang Berhubungan Dengan Pola Pencarian Pengobatan Ke Pelayanan Kesehatan Alternatif Pasien Suspek TuberculosisDi Komunitas. Kesmas, 7(2), 55-112. https://doi.org/https://doi.org/10.1155/2016/3567502

Shaikh, B. T., Haran, D., Hatcher, J., \& Iqbal Azam, S. (2008). Studying health-seeking behaviours: Collecting reliable data, conducting comprehensive analysis. Journal of Biosocial Science, 40(1), 53-68. https://doi.org/https://doi.org/10.1017/S0021932007002118

Short, S. E., Yang, Y. C., \& Jenkins, T. M. (2013). Sex, gender, genetics, and health. American Journal of Public Health, 103(1), 93-101. https://doi.org/https://doi.org/10.2105/AJPH.2013.301229

Windasari, N. N., Wibowo, S., \& Afandi, M. (2014). Pendidikan Kesehatan Dalam Meningkatkan Kepatuhan Merawat Kaki pada Pasien Diabetes Melitus Tipe II. 1, 15. https://doi.org/https://doi.org/10.1007/s13398-014-0173-7.2

\section{(c) (i)}

(C) 2019 Oleh authors. Lisensi Jurnal Solma, LPPM-Uhamka, Jakarta. Artikel ini bersifat open access yang didistribusikan di bawah syarat dan ketentuan Creative Commons Attribution (CC BY) license. (http://creativecommons.org/licenses/by/4.0/). 